\title{
Dr Smarajit Jana (1951-2021): An obituary
}

\author{
SATYA SIVARAMAN, SIDDHARTH DUBE, SWARUP SARKAR
}

In the passing away of Dr Smarajit Jana on May 8, after a battle with Covid-19, India and the world have lost one of the most resourceful and compassionate development workers and a medical professional with the highest standards of ethics in both research and practice.

Born in rural West Bengal bordering Orissa, Dr. Jana came to Kolkata to study in the early seventies and joined the Calcutta National Medical College and Hospitals. From his early student life he was drawn towards work on population health and continued to nurture his understanding of the subject through his postgraduate training in public health.

Starting as a physician in the Employees State Insurance Corporation (ESIC) hospital, he later became a teacher of occupational health and then epidemiology at the All India Institute of Hygiene and Public Health. In 1992, he was asked to carry out the first population-based survey of HIV among sex workers in Sonagachi, Kolkata by the World Health Organization (WHO) and India's National AIDS Control Programme.

Among his many pioneering innovations as part of the survey, Dr Jana first developed a norm for individual and group consent for testing and, importantly, involved the community in designing and implementing the study itself. This approach was in stark contrast to the standard practice, at that time, of enforced, mandatory HIV tests of so-called "high-risk" populations, often carried out with the help of the police, a shameful approach that too many health officials embraced and abetted.

Under Dr Jana's guidance the survey work led to the setting up of the Durbar Mahila Samanwaya Committee (DMSC), a

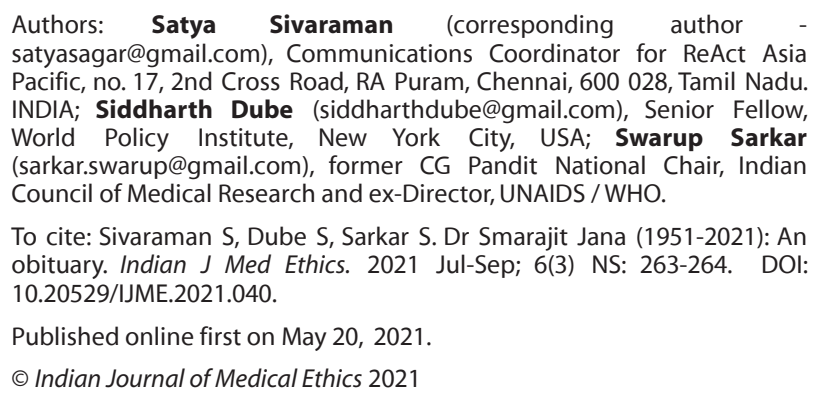

Published online first on May 20, 2021.

(c) Indian Journal of Medical Ethics 2021

path-breaking collective of sex workers that has since given the world invaluable lessons about community leadership of vital health interventions.

Dr Jana's key insight involved the need for recognising sex work as a normal occupation without any social or cultural prejudice, a very bold stand to take in the early nineties. He identified low self-esteem as a major obstacle to sex workers fighting for their rights and began convincing them that they were not any different from other professional groups in society.

Dr Jana also realised that providing medical advice alone was meaningless for marginalised communities like sex workers. If they were to prioritise health, they would need help to solve a host of other crippling problems, including stigma, low social status, pervasive violence by state authorities and criminal gangs. Many of the women were mothers, deeply concerned about the future well-being of their children. Dr Jana opposed efforts by state agencies to separate the children of the sex workers from their mothers. Instead, he helped sex workers establish creches and boarding schools for their young and older children to provide a choice of environment other than the occupational place of their mothers.

Through the DMSC, the sex workers of Sonagachi successfully tackled their myriad social, economic and cultural handicaps. The foundational step was forming a union of sex workers, today with over 60,000 members across West Bengal. They fought against the stigma associated with their work. They fought to be recognised as workers. They fought trafficking and violence. They fought police abuse. They fought economic insecurity by establishing an independent cooperative bank. They fought their families' illiteracy and disadvantages by establishing vocational and educational institutions for their children and for themselves.

Despite a severe shortage of resources, DMSC members themselves became the most ardent campaigners for HIV prevention, using peer education methods to spread the message. The resulting health benefits, coupled with a reduction in violence, were tremendous with HIV rates among Kolkata's sex workers remaining far below other Indian cities which saw soaring HIV infections. While HIV seroprevalence rates among sex workers ranged around $50 \%$ and above in several other cities in the country, 
Calcutta's HIV rates never went up to more than $10 \%$ (1). After the launch of the DMSC initiative, condom use among sex workers' clients rose in Calcutta from 3\% in 1992 to $90 \%$ in 1999, compared with continued lower rates of condom use among clients of sex workers in other Indian cities (1).

In the early 2000s, the Sonagachi Model, as it came to be known around the globe, was also replicated in neighbouring Bangladesh and has been credited for the very low HIV infection rates among sex workers in the country till today. Dr Jana not only helped set up the first peer education project in Bangladesh through CARE International, he later worked there to scale it up nationally. Worldwide, the model inspired the practice of providing a package of services for creating an enabling environment for marginalised communities, as part of HIV prevention and treatment programmes. The package included child care, literacy programmes, self-help, and advocacy with local power structures. First adopted by the Government of India, it later became a global best practice adopted by the Avahan project of the Bill and Melinda Gates Foundation, India, and UNAIDS as well as all major donor programmes.

Dr Jana also contributed to institutionalising essential yet difficult concepts in the governance of public health systems. For example, he initiated a self-regulatory board of sex workers to determine the age of individuals entering the profession, a step that hugely reduced trafficking of minor girls in Kolkata and across the state.

Dr Jana's keen ability to "hear the grass growing" and understand the pulse of the people came from a lifelong involvement with social justice causes, apparent from his student days, particularly among those affected by famine, floods and dire urban poverty. As part of West Bengal's vibrant student movement in the early seventies he was involved in opposing the Emergency imposed across India from 1975 to 1977 . He was part of the Medico Friend Circle an organisation of healthcare providers and activists across India, set up in the mid-70s. His activism continued in the 80s through his involvement with the Bhopal gas disaster relief work, the junior doctors' movement in West Bengal, and the mining-workers' movement for healthcare in Chhattisgarh.

A lesser-known facet of Dr Jana was that he was a prolific writer and author of many popular small, easy-to-read handbooks in Bengali, meant to demystify medicine and medical concepts. This was in keeping with his strong belief that ordinary citizens, could become masters of their own destiny in matters of health as well as life in general. The two journals Drug Disease Doctor for rational use of medicine and the Socialist Health Review, are testimony to this. DurbarBhabna was another journal that was regularly published by the DMSC.

A visionary, leader, teacher, and friend, Dr Smarajit Jana's impact on the many lives he touched is immeasurable and his legacy of work will remain an inspiration for future generations of public health leaders.

Acknowledgements: We would like to thank Debashis Mandal, Manchester, UK, Mrityunjoy Neogi, Kolkata and Samaita Jana, University of Pennsylvania, USA, for their help with comments, information and suggestions.

\section{Reference}

1. Basu I, Jana S, Rotheram-Borus MJ, Swendeman D, Lee SJ, Newman P Weiss R.. HIV prevention among sex workers in India. J Acquir Immune Defic Syndr. 2004;36(3):845-52. Doi:10.1097/00126334200407010-00012. 